\title{
Benefit Effect of Sublingual Dust Mite Drops on the Control of Asthma in Children
}

\author{
Li Wang \\ Tao Ai \\ Ronghua Luo \\ Yinghong Fan \\ Yaping Duan
}

Chengdu Women's and Children's Central Hospital, School of Medicine, University of Electronic Science and Technology of China, Chengdu, 6II73I, People's Republic of China
Correspondence: Tao Ai

Email aitl108@I63.com
Aim: To evaluate the effect of sublingual dust mite drops on inhaled corticosteroid replacement and its effect on asthma control level.

Methods: Two hundred children with asthma who had received regular treatment for one year or more were divided into the observation group (71 cases) and control group (89 cases) according to whether sublingual dust mite drops were added on the basis of conventional treatment drugs. After treatment, C-ACT score, VAS score, drug score, lung function, exhaled nitric oxide level, and "ICS avoidance" were compared between the two groups.

Results: Before treatment, FVC and PEF25 scores in the observation group were lower than those in the control group, and the difference was statistically significant. There was no significant difference in other indicators between the two groups. There was no statistical significance in each index between the single allergic group and the multiple allergic group. Both the observation group and the control group showed statistically significant differences in each index before and after treatment. C-ACT score, FVC, FEV1, PEF, PEF75, PEF50, PEF25, MMEF75/MMEF25 after treatment were all higher than before treatment in both groups; VAS score, drug score and FeNO after treatment were all lower than before treatment. Except PEF, the difference between the observation group and the control group before and after treatment was statistically significant. Among them, after treatment, the increased values of C-ACT, FVC, FEV1, PEF75, PEF50, PEF25, MMEF75/MMEF25 in the observation group were higher than those in the control group, while the decreased values of VAS score, drug score and FeNO were higher than those in the control group. The differences were statistically significant. After treatment, the increased value of $\mathrm{FEV}_{1}$ in the single allergic group was higher than that in the multiple allergic group, and the difference was statistically significant. There was no statistical significance in the changes in other indexes between the two groups before and after treatment. The ICS avoidance rate in the observation group was 57.4\% (58/100), higher than that in the control group $(17.0 \%$, $17 / 100)$, and the difference was statistically significant $(\chi 2=35.108, \mathrm{P}<0.01)$. The ICS avoidance rate was $55.6 \%(15 / 27)$ in the single allergic group and $58.1 \%(43 / 74)$ in the multiple allergic group, and there was no significant difference between the two groups $(\chi 2=0.053, \mathrm{P}=0.818)$.

Conclusion: Sublingual dust mite drops can significantly improve the asthma control levels in children with asthma and have the effect of inhaled corticosteroid replacement.

Keywords: sublingual dust mite drops, asthma, children, pulmonary function

\section{Introduction}

Asthma is the most common chronic respiratory disease in childhood. The third epidemiological survey of childhood asthma in China in 2013 showed that the average two-year incidence rate of asthma among urban children aged 0-14 years 
was $2.32 \%$, and the cumulative prevalence rate was $3.02 \%$ on average. ${ }^{1}$ However, a recent questionnaire survey on adult patients with asthma in China shows that the incidence of asthma among people aged 20 and above in China has reached $4.2 \%$, far exceeding previous estimates. It is speculated that the incidence of asthma in children in China may be higher than the current expected level, this is related to rapid industrialization, environmental pollution and changes in lifestyle. ${ }^{2}$ Asthma control level can be divided into well controlled, partially controlled and uncontrolled. At present, there is no objective standard for the assessment of the condition of children with asthma except the control level of asthma symptoms. Suggestions for the standardized diagnosis and treatment of children with bronchial asthma in China indicate that the use of inhaled corticosteroid (ICS) can be discontinued for children younger than 6 years of age when they are given lowdose ICS and maintain good control for 3-6 months. Children aged 6 and above who maintain good control for more than half a year can try to stop ICS and follow up closely. At present, it is generally believed that sublingual allergen-specific immunotherapy (SLIT) is a safe and effective causative treatment for asthma. ${ }^{3}$ At present, a large number of domestic and foreign literatures have reported that sublingual dust mite drops not only have a significant effect on allergic rhinitis, ${ }^{4}$ but also can significantly relieve the respiratory symptoms of children with asthma and improve the quality of life of patients. ${ }^{5,6}$ Based on this fact, we used avoidance or successful discontinuation of ICS for at least 12 months as objective parameters to evaluate long-term treatment, and to analyze the effect of ICS replacement in SLIT and its effect on asthma control levels.

\section{Methods}

\section{Patients}

From February 2019 to January 2021, 200 children with asthma in our hospital, whose skin prick tests indicated positive results for dust mites, were divided into 2 groups according to the wishes of their parents: 1) Observation group (100 cases): children treated with sublingual dust mites drops, at the same time, according to the condition to use symptomatic treatment drugs for asthma.2) Control group (100 cases): children only use symptomatic treatment drugs for asthma. The children in the observation group were divided into a single allergic group and a multiple allergic group according to whether to incorporate other allergens except dust mites. The study was approved by the ethics board of Chengdu Women and Children Center Hospital and informed consent was taken from all the parents of the patients.

Inclusion principles: 1) Patients were diagnosed and treated according to the standardized diagnosis and treatment recommendations of childhood bronchial asthma $(2020) ;^{7}$ 2) all children were tested for allergens before treatment, and dust mite were positive, with or without other allergens; and 3) children with asthma in the remission stage.

The exclusion criteria: 1) acute asthma (FEV1 less than $70 \%$ of the predicted value); 2) severe allergic reaction; and 3) withdrawal from the study or loss of follow-up due to various reasons.

C-ACT, VAS score, drug score, ICS Initial dose, lung function, and exhaled nitric oxide were evaluated once before enrollment, and the above indexes were repeated every three months after enrollment. According to the Standardized diagnosis and treatment recommendations of childhood bronchial asthma (2020), ${ }^{7}$ if asthma symptoms are well controlled and lung function is stable for more than 3 months, treatment can be downgraded by reducing the ICS dose by $25-50 \%$ every 3 months.

\section{Allergen Testing (SPT)}

All children were discontinued with systemic corticosteroids for four weeks before SPT, leukotriene modulators, antihistamines and Chinese patent medicines containing antihistamines for one week, and anti-allergic drugs for one week. Bilateral forearm curvature was selected, with an interval of $2-3 \mathrm{~cm}$ for each of the two reagents. A drop of prickle solution was inserted into the skin with the prickle needle vertically through the prickle solution with a depth of $0.75 \mathrm{~mm}$. Wipe the residual droplets with cotton swab for 5-10 min. Observed 15-20 min and measured the size of the wind mass. Criteria for positive results: the skin test index was used as the criterion. Skin index (SI) = allergen diameter/histamine diameter. "-":0.0 0 SI $<0.25$;

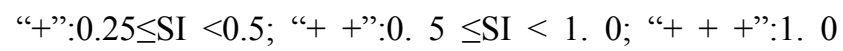
$\leq \mathrm{SI}<2.0 ;$; ++++ , SI $\geq 2.0$.

\section{Treatment}

Treatment plan for children in the control group: According to the Standardized diagnosis and treatment recommendations for childhood bronchial asthma (2020), ${ }^{7}$ ICS, $\beta_{2}$ receptor agonists, anticholinergic drugs, antileukotriene drugs, oral glucocorticoids and other drugs 
were adjusted according to the condition of children and the asthma step treatment plan.

Treatment plan for children in the observation group: on the basis of conventional treatment, combined with sublingual dust mites drops (Zhejiang Wowu Biotechnology Co., Ltd S20060012) which were divided into 1-4 bottles, 1, 2, 3 weeks after the therapy began using dust mites drops NO.1 to 3, from day 1 to day 7 of each week, respectively, at 1, 2, 3, 4, 6, 8, and 10 drops increasing order. After treatment, use Dust Mite Drops No. 4 for maintenance, 3 drops each time, once a day, until the end of the treatment.

\section{Pulmonary Function}

The pulmonary ventilation function of the children was measured by the Master Screen lung function instrument (Jaeger, German). The measurement parameters included determination of forced vital capacity (FVC), forced vital capacity (FVC), forced expiratory volume in 1 second (FEV1) and forced expiratory volume in 1 second take up of the forced vital capacity (FEV1/FVC), maximum peak expiratory flow (PEF), forced expiratory volume in $25 \%, 50 \%$, and $75 \%$ of vital capacity (FEF25, FEF50, FEF75), maximum tidal midexpiratory flow (MMEF). ${ }^{8}$

\section{Determination of Nitric Oxide}

The exhaled nitric oxide (FeNO) was measured by using the exhaled nitric oxide tester (NIOX, MINO, Sweden). FeNO level was detected according to the FeNO standardized monitoring method recommended by the Pulmonary Function Collaboration Group of the Respiratory Group of Pediatrics Society of Chinese Medical Association. ${ }^{9}$

\section{Evaluation Indicators}

The Childhood Asthma Control Test (C-ACT). C-ACT is a simple questionnaire to assess asthma control status, which is based on a child's clinical symptoms over the last 4 weeks. It was jointly developed by Liu et al. ${ }^{10}$ The scale is composed of 7 questions with a full score of 27 points. Questions 1 to 4 are completed independently under the guidance of the same specialist outpatient nurse, and each question gets a score of 0 to 3 points. Questions 5 to 7 are completed by the parents independently, and each question is scored 0 to 5 points. Questions include: 1) How is your asthma today? 2) How much of a problem is asthma when you are running, exercising or playing sports? 3) Do you cough because of asthma? 4) Do you wake up at night because of asthma? 5) In the past 4 weeks, how many days did your child have daytime asthma symptoms? 6) In the past 4 weeks, how many days did your child have wheezing during the day due to asthma? 7) In the past 4 weeks, how many days did your child wake up at night because of asthma? C-ACT score $\leq 19$ indicates uncontrolled asthma, 20-22 is partially controlled, and $\geq 23$ is fully controlled.

Visual analogue scale (VAS) score. It can directly reflect the symptom changes and the affected degree of quality of life of patients, and plays an important role in the assessment of respiratory allergy (Figure 1). ${ }^{11}$

Drug scoring. A quantitative index of the application of symptomatic drugs was used to record the use of symptomatic drugs in the children, so as to evaluate the clinical efficacy of immunotherapy. Our study adopted the "threestep" scoring method (Table 1). ${ }^{12}$

ICS avoided. Children who maintained asthma control and did not use ICS as a control medication for at least 12 months were defined as "ICS avoided."

\section{Statistical Analysis}

SPSS 25.0 software was used for statistical analysis of the data. The quantitative data were described by mean \pm standard deviation or median and upper and lower quartiles, respectively, according to whether the data followed a normal distribution. The observation group and the control group, the single allergic group and the multiple allergic group were compared before and after the treatment of each indicator change value, according to whether the data obey the normal distribution, using two independent samples $t$-test or two independent samples rank sum test. Paired design $t$-test or paired rank sum test were used to compare the indexes in each group before and after treatment according to whether the data followed a normal distribution. ICS avoidance rates were compared between groups using Pearson chi-square test. $\mathrm{P} \leq 0.05$ was considered to be statistically significant.

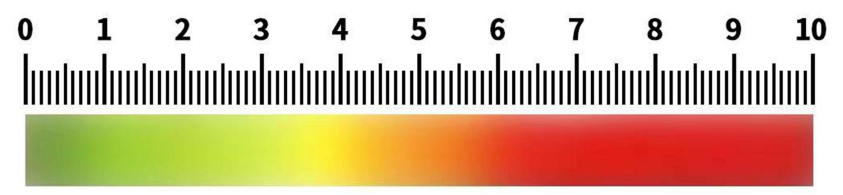

Figure I Visual analogue scale: One end of the picture is 0 , meaning it is no complaints; The other end is 10, which means the most uncomfortable; The middle part represents different levels of discomfort. 
Table I Symptomatic Drug Rating Scale

\begin{tabular}{|l|l|l|}
\hline Grade & \multicolumn{1}{|c|}{ Symptomatic Treatment Drugs } & example \\
\hline I & $\begin{array}{l}\text { Oral and/or topical antihistamines } \\
\text { Antileukotrienes } \\
\text { Bronchodilators }\end{array}$ & $\begin{array}{l}\text { loratadine, Cetirizine hydrochloride, et al Montelukast, et al Salbutamol, Terbutaline, } \\
\text { Ipratropium bromide, et al }\end{array}$ \\
\hline 2 & Nasal corticosteroids/inhaled corticosteroids & Mometasone furoate, Budesonide, et al \\
\hline 3 & $\begin{array}{l}\text { Oral glucocorticoids } \\
\text { Combination therapy (hormone and beta2- } \\
\text { receptor agonist) }\end{array}$ & Prednisone acetate, et al Budesonide Formotero, et al \\
\hline
\end{tabular}

Note:Data from Xiang et al. ${ }^{12}$

\section{Results}

\section{Basic Characteristics}

After 1 year of follow-up, 5 patients in the observation group terminated desensitization due to acute attack of asthma (FEV1 less than $70 \%$ expected value), 9 were lost to followup, 15 voluntarily withdrew, and 71 patients in the observation group completed the study. Among them, 47 (66.2\%) were males and $24(33.8 \%)$ were females. Three patients in the control group were terminated by an acute attack of asthma (FEV1 less than $70 \%$ of the predicted value), 3 patients were terminated, 5 patients were lost to follow-up, 3 patients voluntarily withdrew, and 89 patients completed the study. There were $51(57.3 \%)$ males and 38 (42.7\%) females, respectively, and there was no significant difference in gender composition between the two groups $\left(\chi^{2}=1.316, P=0.251\right)$. The age of the treatment group was $7.2 \pm 2.9$ years old and that of the control group was $7.0 \pm 2.3$ years old. There was no significant difference between the two groups ( $t=0.367, P=0.714$ ). In the observation group, there were 26 patients with single allergy, 6 patients lost follow-up after 1 year of follow-up, 8 patients voluntarily withdrew, 1 patient terminated desensitization treatment due to acute attack of asthma (FEV1 was less than $70 \%$ expected value) during follow-up, and 12 patients completed the study, including 9 males (75.0\%) and 3 females (25.0\%). Among 74 patients with multiple allergies, 3 were lost to follow-up, 8 voluntarily withdrew, 4 patients terminated desensitization treatment due to acute attack of asthma (FEV1 less than $70 \%$ expected value),59 people completed the study, including 38 (64.4\%) males and 21 (35.6\%) females. There was no significant difference in gender composition between the two groups $\left(\chi^{2}=0.139, P=0.710\right)$. The age of single allergic group was $6.5 \pm 3.1$ years old, and that of the multiple allergic group was $7.3 \pm 2.9$ years old. There was no significant difference in age between the two groups $(\mathrm{t}=0.856, P=0.395)$.

Table 2 Comparison of Indexes Before Treatment Between Observation Group and Control Group, Single Allergic Group and Multiple Allergic Group

\begin{tabular}{|c|c|c|c|c|c|c|}
\hline \multirow[t]{2}{*}{ Variable } & \multicolumn{3}{|c|}{ Observation Group vs Control Group } & \multicolumn{3}{|c|}{ Single Allergic Group vs Multiple Allergic Group } \\
\hline & $\begin{array}{l}\text { Observation Group } \\
n=100\end{array}$ & $\begin{array}{c}\text { Control Group } \\
n=100\end{array}$ & $\boldsymbol{P}$ & $\begin{array}{l}\text { Single Allergic Group } \\
\qquad n=26\end{array}$ & $\begin{array}{l}\text { Multiple Allergic Group } \\
\qquad n=74\end{array}$ & $\boldsymbol{P}$ \\
\hline C-ACT score & $15.0(\mid 2.0,19.5)$ & $16.0(12.0,19.0)$ & 0.585 & I8.0 (I2.0,24.0) & $15.0(11.0,19.0)$ & 0.065 \\
\hline VAS score & $4.0(1.0,6.0)$ & $3.0(1.0,5.0)$ & 0.302 & $3.0(1.0,5.0)$ & $4.0(1.0,6.0)$ & 0.305 \\
\hline Drug score & $3.0(3.0,4.0)$ & $3.0(3.0,4.0)$ & 0.108 & $3.0(3.0,4.0)$ & $3.0(3.0,4.0)$ & 0.485 \\
\hline ICS Initial dose & $200.0(200.0,200.0)$ & $200.0(200.0,200.0)$ & 0.077 & $200.0(200.0,200.0)$ & $200.0(200.0,200.0)$ & 0.434 \\
\hline FVC & $91.8 \pm 14.9$ & $96.4 \pm 13.9$ & $0.024^{\mathrm{a}}$ & $89.1 \pm 18.3$ & $92.8 \pm 13.5$ & $0.273^{\mathrm{a}}$ \\
\hline FEVI & $91.4 \pm 15.5$ & $95.5 \pm 15.4$ & $0.066^{\mathrm{a}}$ & $86.8 \pm 18.8$ & $93.1 \pm 13.9$ & $0.119^{\mathrm{a}}$ \\
\hline PEF & $93.7 \pm 15.2$ & $96.5 \pm 17.0$ & $0.188^{a}$ & $92.9 \pm 18.3$ & $94.0 \pm 14.0$ & $0.74 I^{\mathrm{a}}$ \\
\hline PEF75 & $64.5(44.1,78.8)$ & $53.2(43.7,68.6)$ & $0.055^{\mathrm{a}}$ & $65.9(48.7,79.2)$ & $64.5(43.7,78.4)$ & 0.872 \\
\hline PEF50 & $69.4(57.4,86.3)$ & $67.8(57.5,85.9)$ & 0.634 & $68.7 \pm 27.1$ & $73.7 \pm \mid 8.1$ & $0.376^{\mathrm{a}}$ \\
\hline PEF25 & $69.2(53.7,83.3)$ & $76.6(62.8,94.0)$ & 0.003 & $68.2(53.8,83.8)$ & $69.6(53.7,82.8)$ & $0.642^{\mathrm{a}}$ \\
\hline MMEF75/MMEF25 & $69.8 \pm 22.3$ & $69.4 \pm 22.0$ & $0.910^{\mathrm{a}}$ & I8.0 (I2.0,24.0) & $15.0(11.0,19.0)$ & 0.065 \\
\hline FeNO & $28.0(21.0,44.0)$ & $29.5(17.0,55.5)$ & 0.626 & $3.0(1.0,5.0)$ & $4.0(1.0,6.0)$ & 0.305 \\
\hline
\end{tabular}

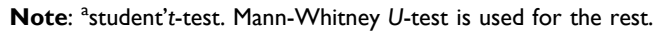


Comparison of Indexes Before Treatment Between Observation Group and Control Group, Single Allergic Group and Multiple Allergic Group

Before treatment, FVC and PEF25 scores in the observation group were lower than those in the control group, and the difference was statistically significant. There was no significant difference in other indicators between the two groups. Before treatment, there was no statistical significance in each index difference between the single allergic group and the multiple allergic group $(\mathrm{P}<0.05)$ (Table 2$)$.

\section{Comparison of Indexes Between Observation Group and Control Group Before and After Treatment}

Both the observation group and the control group showed statistically significant differences in each index before and after treatment. C-ACT score, FVC, FEV1, PEF, PEF75, PEF50, PEF25, MMEF75/MMEF25 after treatment were all higher than before treatment in both groups. VAS score, drug score and FeNO after treatment were all lower than before treatment $(\mathrm{P}<0.05)$ (Table 3$)$.

\section{Comparison of the Improvement of Each Index Before and After Treatment Between Observation Group and Control Group, Single Allergic Group and Multiple Allergic Group}

Except for PEF, the difference between the observation group and the control group before and after treatment was statistically significant. Among them, after treatment, the increased values of ACT, FVC, FEV1, PEF75, PEF50, PEF25, MMEF75/MMEF25 in the observation group were higher than those in the control group, while the decreased values of VAS score, drug score and FeNO were higher than those in the control group. The differences were statistically significant. After treatment, the increased value of FEV1 in the single allergic group was higher than that in the multiple allergic group, and the difference was statistically significant. There was no statistical significance in the changes of other indexes between the two groups before and after treatment $(\mathrm{P}>0.05)$ (Table 4).

The rate of "ICS avoided" in the observation group was $57.4 \%(58 / 101)$, higher than that in the control group $(17.0 \%, 17 / 100)$, and the difference was statistically significant $\left(\chi^{2}=35.108, \mathrm{P}<0.001\right)$. The avoidance rate of ICS was $55.6 \%(15 / 26)$ in the single allergy group and $58.1 \%$ $(43 / 74)$ in the multiple allergy group, with no statistically significant difference between the two groups $\left(\chi^{2}=0.053\right.$, $\mathrm{P}=0.818)$.

\section{Discussion}

Asthma severity assessment in the non-acute attack stage includes clinical assessment based on asthma control level classification and functional assessment based on pulmonary ventilation function measurement. The most commonly used clinical assessment tool for children aged 4 to 11 years is the C-ACT. Measurement of pulmonary ventilation function can provide an objective indicator of the severity of airflow limitation in children, and help to predict the long-term outcome of the disease, which requires regular detection. ${ }^{7}$ Surveys have shown that

Table 3 Comparison of Indexes Between Observation Group and Control Group Before and After Treatment

\begin{tabular}{|c|c|c|c|c|c|c|}
\hline \multirow[t]{2}{*}{ Variable } & \multicolumn{3}{|c|}{ Observation Group } & \multicolumn{3}{|c|}{ Control Group } \\
\hline & Before Treatment & After Treatment & $\boldsymbol{P}$ & Before Treatment & After Treatment & $\boldsymbol{P}$ \\
\hline C-ACT & I5.0 (II.5, I8.5) & $25.5(20.0,27.0)$ & $<0.001$ & $16.0(12.0,19.0)$ & $21.0(19.0,27.0)$ & $<0.001$ \\
\hline VAS score & $4.0(2.0,6.0)$ & $0.0(0.0,1.0)$ & $<0.001$ & $3.0(I .0,5.0)$ & $1.0(0.0,1.0)$ & $<0.001$ \\
\hline Drug score & $3.0(3.0,4.0)$ & $0.0(0.0,2.0)$ & $<0.001$ & $3.0(3.0,4.0)$ & $3.0(2.0,3.0)$ & $<0.001$ \\
\hline FVC & $90.7(83.0,98.2)$ & $102.5(96.0,109.8)$ & $<0.001$ & $96.8(87.2,105.2)$ & $105.6(96.1,110.3)$ & $<0.001$ \\
\hline FEVI & $90.8(80.9,98.4)$ & I04.I (95.2, II 3.5$)$ & $<0.001$ & $96.0(86.1,104.4)$ & $102.8(98.3,110.8)$ & $<0.001$ \\
\hline PEF & $92.5 \pm 14.1$ & $104.3 \pm 15.2$ & $<0.001^{a}$ & $95.2(83.7,106.7)$ & $105.8(98.5,116.5)$ & $<0.001$ \\
\hline PEF75 & $62.1 \pm 21.6$ & $88.2 \pm 24.6$ & $<0.001^{\mathrm{a}}$ & $51.6(43.1,64.3)$ & $68.9(58.9,74.5)$ & $<0.001$ \\
\hline PEF50 & $67.9(56.8,84.1)$ & $92.2(73.7,104.9)$ & $<0.001$ & $65.8(56.5,80.9)$ & $78.6(67.8,86.9)$ & $<0.001$ \\
\hline PEF25 & $69.7 \pm 22.7$ & $92.9 \pm 24.8$ & $<0.001^{\mathrm{a}}$ & $76.7(62.5,94.5)$ & $89.0(73.9,100.1)$ & $<0.001$ \\
\hline MMEF75/MMEF25 & $67.6(53.9,78.0)$ & $92.0(68.4,102.7)$ & $<0.001$ & $64.9(54.7,79.6)$ & $78.4(68.7,89.9)$ & $<0.001$ \\
\hline FeNO & $30.5(23.0,45.0)$ & I $5.0(|| .0,23.0)$ & $<0.001$ & $33.0(17.0,56.0)$ & $19.0(\mid 5.0,32.0)$ & $<0.001$ \\
\hline
\end{tabular}

Note: ${ }^{a}$ student't-test. Mann-Whitney $U$-test is used for the rest. 
Table 4 Comparison of the Improvement of Each Index Before and After Treatment Between Observation Group and Control Group, Single Allergic Group and Multiple Allergic Group

\begin{tabular}{|c|c|c|c|c|c|c|}
\hline \multirow[t]{2}{*}{ Variable } & \multicolumn{3}{|c|}{ Observation Group vs Control Group } & \multicolumn{3}{|c|}{ Single Allergic Group vs Multiple Allergic Group } \\
\hline & $\begin{array}{l}\text { Observation Group } \\
\qquad \mathrm{n}=100\end{array}$ & $\begin{array}{c}\text { Control Group } \\
n=100\end{array}$ & $\mathbf{P}$ & $\begin{array}{l}\text { Single Allergic Group } \\
\qquad \mathrm{n}=\mathbf{2 6}\end{array}$ & $\begin{array}{l}\text { Multiple Allergic Group } \\
\qquad n=74\end{array}$ & $\mathbf{P}$ \\
\hline C-ACT & $8.0(6.0,12.0)$ & $7.0(4.0,9.0)$ & 0.001 & $8.0(6.5,12.5)$ & $8.5(6.0,12.0)$ & 0.960 \\
\hline VAS score & $-3.0(-5.0,-1.0)$ & $-2.0(-4.0,-1.0)$ & 0.019 & $-3.5(-4.0,-1.5)$ & $-3.0(-5.0,-1.0)$ & 0.806 \\
\hline Drug score & $-3.0(-4.0,-2.0)$ & $-1.0(-1.0,0.0)$ & $<0.001$ & $-3.0(-4.0,-2.0)$ & $-3.0(-4.0,-2.0)$ & 0.784 \\
\hline FVC & $12.4(4.3,19.7)$ & $6.6(1.1,11.1)$ & $<0.001$ & I $4.3(I .8,26.2)$ & $11.9(4.6,17.8)$ & 0.716 \\
\hline FEVI & $15.4(4.2,24.8)$ & $7.2(2.1,12.6)$ & 0.001 & $20.8(10.2,31.6)$ & $12.9(4.0,22.3)$ & 0.042 \\
\hline PEF & $12.4(2.8,22.0)$ & $9.5(4.0,17.0)$ & 0.256 & $13.9 \pm 14.6$ & $11.2 \pm 17.2$ & $0.523^{\mathrm{a}}$ \\
\hline PEF75 & $23.4(6.1,45.3)$ & $12.0(4.8,21.9)$ & 0.002 & $28.1 \pm 3 I . I$ & $25.5 \pm 30.4$ & $0.734^{\mathrm{a}}$ \\
\hline PEF50 & $17.8(5.1,35.1)$ & $7.9(-0.6,21.5)$ & 0.001 & $22.9(5.9,47.4)$ & I7.7 $(5.7,33.3)$ & 0.376 \\
\hline PEF25 & $23.2(6.7,37.1)$ & $8.6(-0.2,15.6)$ & $<0.001$ & $22.2(2.1,47.6)$ & $23.2(7.1,35.2)$ & 0.724 \\
\hline MMEF75/MMEF25 & $17.8(8.2,33.1)$ & $9.8(4.9,16.8)$ & 0.004 & $18.3(-2.0,48.7)$ & I7.5 (9.2,28.7) & 0.819 \\
\hline $\mathrm{FeNO}$ & $-13.5(-2 \mid .5,-7.0)$ & $-9.0(-22.0,-2.0)$ & 0.039 & $-15.5(-24.5,-9.0)$ & $-13.0(-20.5,-7.0)$ & 0.654 \\
\hline
\end{tabular}

Note: ${ }^{a}$ student't-test. Mann-Whitney U-test is used for the rest.

more than $20 \%$ of children with asthma fail to achieve good control. ${ }^{13}$ Global initiatives of asthma (GINA2020) guide $^{14}$ and the children bronchial asthma diagnosis and control guide of China $(2020)^{7}$ recommend ICS as the drug of choice for long-term management of childhood asthma in remission, but research shows that children's ICS medication adherence is usually less than $50 \% .{ }^{15}$ It is suggested that the poor compliance of long-term use of ICS in children with asthma is one of the main reasons for the recurrence of asthma symptoms and poor control level in children. ${ }^{16}$ A study on children showed that the adherence to asthma medication reached $86.9 \%$ in $1-3$ months, decreased to $65.0 \%$ in 4-6 months, and continued to decrease to $52.5 \%$ in $7-12$ months. It is suggested that medication compliance of children with asthma is poor and decreases with the increase in treatment time, ${ }^{17}$ and the possible influencing factors are further investigated. The results showed that the most important factor affecting medication compliance of children was parents' concern about adverse reactions of long-term medication. ${ }^{18}$

Allergen-specific immunotherapy (AIT) includes sublingual allergen-specific immunotherapy (SLIT) and subcutaneous specific immunotherapy (SCIT). Sublingual allergen-specific immunotherapy prevents allergy by inducing the production and activation of Treg cells and Breg cells, regulating the immune response mediated by allergen-specific IgE and IgG antibodies, and inhibiting mast cell and basophil degranulation to suppress allergic inflammation. ${ }^{19}$ Sublingual dust mite drops are the only standardized sublingual allergen-specific immunotherapy allergen preparation for children in China. In 2013, the World Allergy Organization (WAO) pointed out in its position paper on sublingual allergen-specific immunotherapy $(\text { SLIT) })^{20}$ that SLIT has a clear therapeutic effect and reliable safety for asthma patients. Our previous studies have also confirmed that sublingual allergen-specific immunotherapy can relieve respiratory symptoms in children with asthma, reduce the use of symptomatic drugs, and improve the quality of life of patients. ${ }^{21,22}$ Wang et al ${ }^{23}$ found that sublingual mite allergen immunotherapy was well tolerated in adult patients with asthma and was effective in controlling the disease in patients with moderate persistent asthma. However, there is still a lack of research on the effects of dust mite drops under the tongue on the control level and lung function of children with asthma. A study of children with asthma who were allergic to house dust mites treated with SLIT showed that after 3 years of follow-up, SLIT not only reduced the use of inhaled glucocorticoids but also improved lung function. ${ }^{24}$ However, there is still a lack of objective and quantitative evaluation indicators to show whether dust mite drops can have an ICS replacement effect. In this way, parents' concerns about long-term use of ICS can be alleviated, and compliance can be increased, so that asthma in children can be better controlled.

The results of this study showed that asthma symptoms, lung function and FeNO were significantly improved in the observation group and the control group after treatment. However, the observation group had better asthma symptom control than the treatment group, and the 
improvement of lung function and FeNO was more obvious. A recent meta analysis abroad also found that specific immunotherapy can significantly reduce the shortterm symptoms and drug scores of allergic asthma. ${ }^{25}$ Another systematic analysis has shown that specific immunotherapy may reduce symptoms and drug scores, but there is no clear evidence that it improves lung function. ${ }^{26}$ At present, only $\mathrm{Liu}^{27}$ et al have studied the effect of SLIT on ACT in adult asthma patients, and this study showed that the ACT score of patients treated with SLIT was significantly better than that of patients without SLIT, which was consistent with the conclusion of our study. Therefore, we believe that the addition of SLIT can significantly improve the symptom control level of children with asthma. This study also showed that more children with asthma achieved "ICS avoided" after the addition of SLIT treatment, and the effect was significant in children with single or multiple allergies, which was consistent with the conclusions of Bahceciler et al. ${ }^{28}$ The study retrospectively analyzed 90 children with asthma (56.7\% of whom had multiple allergies) who were treated with SLIT for three years. 70\% of them avoided ICS for 6 months, and there was no significant difference between patients with mono-sensitivity and multi sensitivity. The longer duration of SLIT resulted in a higher likelihood of "ICS avoided". A Danish scholar conducted a study on mild-moderate asthma patients over 14 years old who were allergic to dust mites, and found that the dose of ICS could be moderately reduced after 1 year of Slit treatment. ${ }^{29}$ These results highlight the important role of SLIT in reducing the dose or duration of ICS in children with asthma. Therefore, we believe that SLIT may have a glucocorticoid replacement effect and is worthy of further study.

\section{Ethical Statement}

All procedures performed in this study involving human participants were in accordance with the Declaration of Helsinki (as revised in 2013). The study was approved by the ethics board of Chengdu Women and Children Center Hospital and informed consent was taken from all the patients (Approval No.: Scientific Research Renren No. 2020 (20)).

\section{Funding}

Health and Family Planning research project in Sichuan Province (2019).

\section{Disclosure}

The authors report no conflicts of interest in this work.

\section{References}

1. National Pediatric Asthma Collaborating Group, Institute of Environmental and Health-Related Product Safety. The third epidemiological survey of childhood asthma in urban China. $J$ Pediatr. 2013;51(10):729-735.

2. Huang K, Yang T, Xu J, et al. Prevalence, risk factors, and management of asthma in China: a national cross-sectional study. Lancet. 2019;394(10196):407-418. doi:10.1016/S0140-6736(19)31147-X

3. Alvaro-Lozano M, Akdis CA, Akdis M, et al. EAACI allergen immunotherapy user's guide. Pediatr Allergy Immunol. 2020;31 (Supp125):1-101. doi:10.1111/pai.13189

4. Chen WB, Shen XF, Li Q, Zhou WC, Cheng L. Efficacy of a 3-year course of sublingual immunotherapy for mite-induced allergic rhinitis with a 3-year follow-up. Immunotherapy. 2020;12(12):891-901. doi:10.2217/imt-2020-0006

5. Giannetti A, Ricci G, Procaccianti M, et al. Safety, efficacy, and preventive role of subcutaneous and sublingual allergen immunotherapy for the treatment of pediatric asthma. $J$ Asthma Allergy. 2020;13:575-587. doi:10.2147/JAA.S234280

6. Besh L, Slyuzar Z, Matsyura O. [Optimization of allergen-specific immunotherapy in children with bronchial asthma: selection features, patient monitoring and efficacy]. Georgian Med News. 2020; (306):67-72. [swedish]

7. Respiratory Group of Pediatrics Branch of Chinese Medical Association, Children Respiratory Committee of Pediatrics Branch of Chinese Medical Doctor Association. Recommendations for standardized diagnosis and treatment of childhood bronchial asthma (2020). Chin J Pediatr. 2020;9:708-717.

8. Pulmonary function group, respiratory branch, Chinese medical association. Guidelines for pulmonary function examination (part II) spirometry examination. Zhonghua Jie He He Hu Xi Za Zhi. 2014;37:481-486.

9. Pulmonary Function Cooperative Group, Respiratory Group, Pediatrics Society, Chinese Medical Association. Guidelines for indicators of lung function and airway nontraumatic inflammation in children (7): monitoring exhaled nitric oxide. Chin J Pract Pediatr. 2017;32(21):1622-1627.

10. Liu AH, Zeiger R, Sorkness C, et al. Development and cross-sectional validation of the childhood asthma control Test. $J$ Allergy Clin Immunol. 2007;119(4):817-825. doi:10.1016/j. jaci.2006.12.662

11. Bousquet PJ, Combescure C, Neukirch F, et al. Visual analog scales can assess the severity of rhinitis graded according to ARIA guidelines. Allergy. 2007;62(4):367-372. doi:10.1111/j.13989995.2006.01276.x

12. Xiang L, Zhao J, Bao Y, et al. Expert consensus on acariespecific immunotherapy for airway allergic diseases in children. Chin J Appl Pediatr. 2015;33:1215-1223.

13. Xiang L, Zhao J, Zheng Y, et al. Uncontrolled asthma and its risk factors in Chinese children: a cross-sectional observational study. J Asthma. 2016;53(7):699-706. doi:10.3109/02770903.2016.1144199

14. Global Initiative for Asthma. Global strategy for asthma management and prevention; 2020. Available from: www.ginasthma.org. Accessed June 23, 2021.

15. Li HM, Jiang ZF, Zhao SY. Research progress of refractory asthma in children. Int J Pediatr. 2005;(02):113-115.

16. Klok T, Kaptein AA, Brand PLP. Non-adherence in children with asthma reviewed: the need for improvement of asthma care and medical education. Pediatr Allergy Immunol. 2015;26(3):197-205. doi:10.1111/pai.12362 PMID: 25704083. 
17. Gao Y, Pan JP, Wang JM. Investigation and analysis of influencing factors for compliance of inhaled glucocorticoid therapy in children with asthma. Shaanxi Med J. 2014;43(07):916-917.

18. Wei YC, Jia LL, Hu LH, et al. Investigation on compliance of inhaled glucocorticoids in children with asthma in remission period. Chin J Hosp Pharm. 2019;14:1494-1498.

19. Pelaia C, Vatrella A, Lombardo N, et al. Biological mechanisms underlying the clinical effects of allergen-specific immunotherapy in asthmatic children. Expert Opin Biol Ther. 2018;18(2):197-204. doi:10.1080/14712598.2018.1402003

20. Canonica GW, Cox L, Pawankar R, et al. Sublingual immunotherapy: world Allergy Organization position paper 2013 update. World Allergy Organ J. 2014;7:6.

21. Wang L, Ai T, Luo R, et al. Effects of sublingual duster mite drops on lung function and exhaled nitric oxide in children with multiple and single allergic respiratory diseases. Can Respir J. 2020;2020:7430936. doi:10.1155/2020/7430936

22. Ai T, Wang L, Luo R, et al. Effects of sublingual-specific immunotherapy on pulmonary function and exhaled nitric oxide levels in asthmatic children with and without allergic rhinitis. Transl Pediatr. 2020;9(5):686-694. doi:10.21037/tp-20-322

23. Wang L, Yin J, Fadel R, Montagut A, de Beaumont O, Devillier P. House dust mite sublingual immunotherapy is safe and appears to be effective in moderate, persistent asthma. Allergy. 2014;69 (9):1181-1188. doi:10.1111/all.12188

24. Ozdemir C, Yazi D, Gocmen I, et al. Efficacy of long-term sublingual immunotherapy as an adjunct to pharmacotherapy in house dust mite-allergic children with asthma. Pediatr Allergy Immunol. 2007;18(6):508-515. doi:10.1111/j.13993038.2007.00549.x
25. Dhami S, Kakourou A, Asamoah F, et al. Allergen immunotherapy for allergic asthma: a systematic review and meta-analysis. Allergy. 2017;72(12):1825-1848. doi:10.1111/all.13208

26. Asamoah F, Kakourou A, Dhami S, et al. Allergen immunotherapy for allergic asthma: a systematic overview of systematic reviews. Clin Transl Allergy. 2017;7(1):25. doi:10.1186/s13601-017-0160-0

27. Liu W, Jiang $\mathrm{H}, \mathrm{Pu} \mathrm{H}$, et al. [An assessment of the sublingual immunotherapy with Dermatophagoides farinae on asthma control level and pulmonary function of allergic asthma and rhinitis in adult patient]. Lin Chung Er Bi Yan Hou Tou Jing Wai Ke Za Zhi. 2019;33(9):850-854. doi:10.13201/j.issn.1001-1781.2019.09.013 Chinese.

28. Nadir Bahceciler N, Galip N, Babayigit A. Steroid sparing effect of sublingual immunotherapy: real life study in mono/polisensitized children with asthma. Immunotherapy. 2017;9(15):1263-1269. doi:10.2217/imt-2017-0110

29. Mosbech H, Deckelmann R, de Blay F, et al. Standardized quality (SQ) house dust mite sublingual immunotherapy tablet (ALK) reduces inhaled corticosteroid use while maintaining asthma control: a randomized, double-blind, placebo-controlled trial. J Allergy Clin Immunol. 2014;134(3):568-575.e7. doi:10.1016/j.jaci.2014.03.019
International Journal of General Medicine

\section{Publish your work in this journal}

The International Journal of General Medicine is an international, peer-reviewed open-access journal that focuses on general and internal medicine, pathogenesis, epidemiology, diagnosis, monitoring and treatment protocols. The journal is characterized by the rapid reporting of reviews, original research and clinical studies

\section{Dovepress}

across all disease areas. The manuscript management system is completely online and includes a very quick and fair peer-review system, which is all easy to use. Visit http://www.dovepress.com/ testimonials.php to read real quotes from published authors. 